\title{
Bacteriological and Fungal Profile of Otitis Media
}

\author{
R.M. Bala Ashwathy and P. Neelusree* \\ Department of Microbiology, Saveetha Medical College, Chennai, India \\ *Corresponding author:
}

\begin{tabular}{l} 
Ke y w o r d s \\
$\begin{array}{l}\text { Otitis media, Acute } \\
\text { otitis media, Otitis } \\
\text { media with } \\
\text { effusion, Chronic } \\
\text { suppurative otitis } \\
\text { media }\end{array}$ \\
\hline Article Info \\
$\begin{array}{l}\text { Accepted: } \\
\text { 04 August } 2019 \\
\text { Available Online: } \\
\text { 10 September } 2019\end{array}$ \\
\hline
\end{tabular}

A B S T R A C T

Otitis Media is inflammation of the middle ear, which often causes hearing loss. It is one of the common ear infections addressed very frequently. Appropriate treatment at right time is necessary to prevent adverse complications. The common bacteria causing Otitis Media are Pseudomonas aeruginosa, Staphylococcus aureus, Acinetobacter species, Enterobacter species, Escherichia coli, Proteus mirabilis and common fungi causing otitis media are mainly Candida non albicans and Aspergillus species. The aim of the study was to isolate the common bacterial and fungal agents causing Otitis Media and to find the antibiotic susceptibility pattern of those bacterial isolates. A retrospective study was carried out in a tertiary care hospital on patients with otitis media. Samples received in the lab and processed by standard methods were analyzed. A total of 79 samples were analyzed during the period of 1 year from Jan 2018 to Dec 2018. On statistical analysis, male patients were more prone to develop infection than the female patients. Also patients of the age group 51 years and more were affected mainly. Among the bacterial isolates, Pseudomonas aeruginosa were found to be predominant followed by Staphylococcus aureus. Among the fungal isolates, Candida non albicans were found to be predominant, followed by Aspergillus species. Majority of the bacterial gram positive isolates were found to be sensitive to Vancomycin, Linezolid and gram negative isolates were found sensitive to combination drugs Piperacillin-tazobactum. With time the bacteria are developing resistance to the antibiotics. Hence treatment at the appropriate stage with suitable drug and dose is significant in preventing complications due to Otitis Media.

\section{Introduction}

Otitis media is an inflammation of the middle ear. It could be acute otitis media (AOM), otitis media with effusion (OME) and chronic suppurative otitis media (CSOM). Acute otitis media is acute infection of the middle ear. Otitis media with effusion, also called the serous otitis media, is accumulation of fluid in the middle ear in the absence of symptoms of acute infection. Chronic suppurative otitis media is persistent inflammation of middle ear with the accumulated fluid inside.

The most common organisms causing Otitis media are Pseudomonas aeruginosa, Staphylococcus aureus, Acinetobacter species, Enterobacter species, Proteus mirabilis, E. 
coli, Candida non albicans, Aspergillus species.

Treatment for Otitis media includes administration of antibiotics like Vancomycin, Linezolid for gram positive organisms and Imipenem, Piperacillin-tazobactum etc for gram negative organisms.

The main objectives of this study, to identify the common bacterial and fungal agents causing Otitis media in patients attending Saveetha Medical College and Hospital. And to determine the antibiotic susceptibility pattern of those bacterial isolates. Demographic analysis of the study patients.

\section{Materials and Methods}

This is a retrospective study carried out in a tertiary care hospital. The study is based on the outcomes of Microbiology laboratory findings from the samples collected from the patients with complaints of ear discharges and ear pain. The ear discharge was collected with sterile cotton swabs taking all aseptic precautions into account. In the laboratory the bacterial isolates were identified using standard methods such as gram staining and culture onto Blood agar, chocolate agar and Mac-conkey agar and routine biochemical tests by using BacT/ ALERT 3D, VITEK2 like instruments.

The fungal isolates were identified by LPCB staining and by culturing onto Sabaurauds dextrose agar. Antimicrobial Susceptibility was carried out using antibiotics like Ampicillin, Amikacin, Gentamicin, Cefoperazone - sulbactum, Piperacillintazobactum, Imipenem, Meropenem, Cotrimoxazole, Polymyxin-B, Cefotaxime, Ciprofloxacin for gram negative organisms, Erythromycin, Clindamycin, Vancomycin, Linezolid, Penicillin, Cefoxitin, Ciprofloxacin for gram positive organisms.

\section{Results and Discussion}

A retrospective study was carried out in a tertiary care hospital, Chennai. A total of 79 patients showing symptoms of Otitis Media in the past one year Jan 2018 - Dec 2018 were analyzed in this study. This study included both inpatients and outpatients from ENT department. Demographic details of all the study subjects were analyzed in detail. The study showed among them, 42 were males and 37 were females. The male and female distribution of the study subjects were shown in Figure 1.

Age-wise analysis was done, this study showed that all age groups are generally affected with otitis media. But according to our study the more common age group affected were 51 years and more comparatively. Age wise distribution of the study subjects is shown in detail in Figure 3.

A total of 79 samples collected from patients were investigated in Microbiology Laboratory through standard methods were included in this study. On analyzing the most common causative microorganisms isolated from otitis media patients, in our study predominantly bacterial and very few fungal isolates were isolated. Distribution of the common etiological agents from patients with otitis media is shown in Figure 2.

Though both bacterial and fungal agents are significantly important in causing Otitis media, in some cases, the microorganisms produced infection in association with each other. In our study we found that it is not just a single bacterial or fungal isolate causing otitis media, it's a mixture of both bacterial and fungal agents causing infection in association with each other. Bacterial agent with super added fungal agent or fungal infection with super added bacterial agents. This co-infection pattern is clearly explained in Table 1 . 
Out of 79 samples analyzed, 55 ( 69.5\%) were positive for bacteria and $8(10 \%)$ were positive for fungi. distribution of etiological agents causing otitis media shown in Table 2, Figure 4 and 5.

The most predominant bacterial isolates were Pseudomonas aeruginosa, 18 (32.2\%), followed by Staphylococcus aureus, 12 (21.5\%). Other species were CoagulaseNegative Staphylococci, 9 (16.1\%), Acinetobacter baumannii, 3 (5.3\%), Escherichia coli, 3 (5.3\%), Enterobacter cloacae, 3 (5.3\%), Proteus mirabilis, 2 (3.6\%), Enterobacter aerogenes, 1 ( 1.8\%), and MRSA (Methicillin-resistant Staphylococcus aureus, 1 (1.8\%) in the order of predominance. The detailed distribution of the organisms shown in Table 3. The fungal isolates were Candida non albicans, Aspergillus fumigatus, Aspergillus niger and other Aspergillus species.

The sensitivity pattern of each isolate against different antibiotics is shown in Table 4. Pseudomonas aeruginosa, the predominant bacterial isolate, is sensitive to antibiotics like Amikacin, Imipenem, Chlorpheniramine, Gentamicin, Piperacillin-tazobactum, Meropenem and highly resistant to Ciprofloxacin and Cotrimoxazole. Staphylococcus aureus, the second predominant bacterial isolate, is sensitive to Linezolid, Vancomycin, Gentamicin and highly resistant to Ciprofloxacin, Ofloxacin and Cotrimoxazole.

Otitis Media is the infection of middle ear. It is one of the common ear infections. Ear pain, ear discharges, fever, hearing loss is some symptoms of Otitis Media. If left untreated, it may lead to complications like Labyrinthitis (Otitis Interna; infection of internal ear), Hearing loss (conductive and sensorineural), Mastoiditis (spread of infection to mastoid space behind the ear), and rarely spreads to
CNS causing bacterial meningitis, brain abscess, Dural sinus thrombosis, etc. Thus starting the treatment as soon as possible is important to prevent these complications. In this study some bacteria and fungi were found to be the causative microorganisms of Otitis Media, from the samples collected from the 79 patients. Among them male were found to be predominantly affected than the female patients. This study correlates with the study report of Saranya et.al ${ }^{1}$ but contradicts with the report of Asifa Nazir et.al ${ }^{4}$. Age-wise, patients of age 51 years and more were affected more in our study. This is because of risk factors like smoking, immunosuppression in conditions like diabetes mellitus or use of immunosuppressant. The age-wise analysis by Sunilkumar et al., ${ }^{2}$ shows that age group 51 and more are affected mainly after age group 0-10 years. But the other references $[1],[3],[4],[5],[6]$ support the age group 0-10 years to be mainly affected and very few above 50 years of age to be affected.

After laboratory investigations of the specimens, about $79.5 \%$ of cases gave positive results. The infection was found to be mainly caused by bacteria than fungi. This is supported by reports of Saranya et al., ${ }^{1}$, Sunilkumar et al., ${ }^{[2]}$. There is also evidence of infections involving more than one microorganism i.e. the microorganisms caused infection in association with each other. Among the bacterial isolates, Pseudomonas aeruginosa (32.2\%) and Staphylococcus aureus $(21.5 \%)$ were predominant, followed by Coagulase-negative Staphylococci (16.1\%), Acinetobacter species (7.1\%), Escherichia coli (5.3\%), Enterobacter cloacae (5.3\%), Enterobacter aerogenes (1.8\%), Proteus mirabilis $(3.6 \%)$ and Methicillinresistant Staphylococcus aureus (1.8\%). This correlates with the reports of Sunilkumar et.al [2] and Asifa Nazir et al., ${ }^{[4]}$. But Staphylococcus aureus is reported to be predominant in Krista Vidya et al., ${ }^{[3]}$ report. 
Among the fungal isolates, Candida non albicans $(6.3 \%)$ followed by Aspergillus species $(4.9 \%)$ were predominant. These fungal isolates are reported to cause Otitis Media in other related articles too.

The organisms becoming resistant to different antibiotics with time, the antibiotic profile of the isolates is also assessed in our study. From the pattern observed, Gentamicin, Vancomycin, Linezolid are most effective antibiotics, followed by Piperacillintazobactum, Amikacin, Chlorpheniramine, Imipenem, Erythromycin, Meropenem, Ceftazidine for many isolates. But, Gentamicin and Amikacin being amino glycoside antibiotics are likely to cause ototoxicity and nephrotoxicity. Hence Betalactam antibiotics like Vancomycin, Piperacillin-tazobactum, Imipenem, being more effective and beneficial to amino glycoside antibiotics, are preferred in treating Otitis media.

Pseudomonas aeruginosa, the predominant bacterial isolate, is sensitive to antibiotics like Amikacin, Imipenem, Chlorpheniramine, Gentamicin, Piperacillin-tazobactum, Meropenem and highly resistant to Ciprofloxacin. This corresponds with antibiotic susceptibility pattern of Pseudomonas aeruginosa in Krista Vidya et al., ${ }^{[3]}$ article, but they show more resistance to Piperacillin and more sensitive to Ciprofloxacin after Amikacin.

Staphylococcus aureus, the second predominant one, is sensitive to Linezolid, Vancomycin, Gentamicin and highly resistant to Ciprofloxacin, Ofloxacin and Cotrimoxazole. This corresponds with antibiotic susceptibility pattern of Staphylococcus aureus in Krista Vidya et al., ${ }^{[3\}}$ article.

Coagulase-negative Staphylococci, are sensitive to Vancomycin, Linezolid,
Gentamicin and resistant to Ciprofloxacin, Cotrimoxazole, Clindamycin. This has not been reported in any of the articles referred so far in our study. The same applies for MRSA.

Methicillin-resistant Staphylococcus aureus [MRSA], are sensitive to Vancomycin, Linezolid. Vancomycin resistance is on increase among MRSA isolates. Proper usage of Vancomycin would reduce the VR-MRSA.

Acinetobacter species, are sensitive to Piperacillin-tazobactum and resistant to Ampicillin, Chlorpheniramine, Ciprofloxacin. Acinetobacter species is reported to cause Otitis Media in Krista Vidya et.al ${ }^{[3\}}$ article also. ESBL producing Acinetobacter are commonly isolated from otitis media patients hence the combination of Beta-lactam + Beta lactamase (Piperacillin-tazobactum) would be the prescribed drug against these isolates.

Escherichia coli, is sensitive to Piperacillintazobactum and resistant to Ampicillin.

Enterobacter species, are sensitive to Imipenem and resistant to Ciprofloxacin.

Proteus mirabilis, is sensitive to Piperacillintazobactum, Chlorpheniramine, Amikacin and resistant to Cotrimoxazole.

Escherichia coli, Proteus mirabilis, Enterobacter species have been reported in nearly all the reports. They have also reported Klebsiella pneumoniae to cause Otitis Media, but our study doesn't report any such finding.

According to our study the commonest organisms causing Otitis media is Pseudomonas and Staphylococcus aureus in concordance with all other studies universally done. Vancomycin and Linezolid would be the drugs for gram positive organisms and combination drugs would be the prescribed drugs for gram negative organisms to treat otitis media. 
Also other studies referred haven't reported Candida non albicans so far but they do report involvement of other Candida species in the fungal isolates. Among fungal isolates
Candida species and Aspergillus species are the most common organisms causing otitis media. In our study, antifungal susceptibility for these isolates is not carried out due to cost factor.

Table.1 Association of bacteria and fungi causing otitis media

\begin{tabular}{|l|l|}
\hline MICROORGANISMS & NO. OF CASES \\
\hline BACTERIA + FUNGI & \multicolumn{2}{|l|}{} \\
\hline $\begin{array}{l}\text { Staphylococcus haemolyticus + Candida non albicans } \\
\text { MS-CoNS + Candida non albicans }\end{array}$ & 1 \\
\hline BACTERIA + BACTERIA & 1 \\
\hline $\begin{array}{l}\text { Staphylococcus aureus + Enterobacter cloacae } \\
\text { Staphylococcus aureus + Pseudomonas aeruginosa } \\
\text { MS-CoNS + Pseudomonas aeruginosa }\end{array}$ & 1 \\
\hline FUNGI + FUNGI & 1 \\
\hline Candida non albicans + Aspergillus niger & 1 \\
\hline
\end{tabular}

Table.2 Bacterial and fungal culture results

\begin{tabular}{|l|c|c|c|c|}
\hline \multirow{2}{*}{ RESULT } & \multicolumn{2}{|c|}{ BACTERIA } & \multicolumn{2}{c|}{ FUNGI } \\
\cline { 2 - 5 } & MALE & FEMALE & MALE & FEMALE \\
\hline POSITIVE & $30(37.9 \%)$ & $25(31.6 \%)$ & $2(2.5 \%)$ & $6(7.5 \%)$ \\
\hline NEGATIVE & $12(15.2 \%)$ & $12(15.2 \%)$ & $40(50.6 \%)$ & $31(39.2 \%)$ \\
\hline TOTAL & $\mathbf{4 2}(\mathbf{5 3 \%})$ & $\mathbf{3 7}(\mathbf{4 7 \%})$ & $\mathbf{4 2}(\mathbf{5 3 \%})$ & $\mathbf{3 7}(\mathbf{4 7 \%})$ \\
\hline
\end{tabular}

Table.3 Distribution of bacterial isolates

\begin{tabular}{|l|r|r|}
\hline BACTERIA & No. of Cases & Percentage \\
\hline Pseudomonas aeruginosa & 18 & $32.70 \%$ \\
\hline Staphylococcus aureus & 12 & $21.80 \%$ \\
\hline CoNS & 9 & $16.30 \%$ \\
\hline Acinetobacter species & 4 & $7.20 \%$ \\
\hline Acinetobacter baumannii & 3 & $5.40 \%$ \\
\hline Escherichia coli & 3 & $5.40 \%$ \\
\hline Enterobacter cloacae & 3 & $5.40 \%$ \\
\hline Enterobacter aerogenes & 1 & $1.80 \%$ \\
\hline Proteus mirabilis & 2 & $3.60 \%$ \\
\hline MRSA & 1 & $1.80 \%$ \\
\hline
\end{tabular}


Table.4 Antibiotic sensitivity of bacteria isolated from samples collected from patients with otitis media

\begin{tabular}{|c|c|c|c|c|c|c|c|c|c|c|c|c|c|c|c|c|c|c|c|c|}
\hline \multirow{2}{*}{$\begin{array}{l}\text { S.N } \\
\text { o }\end{array}$} & \multirow[t]{2}{*}{ ORGANISM } & \multicolumn{19}{|c|}{ ANTIBIOTIC PROFILE } \\
\hline & & $\mathbf{A}$ & $\begin{array}{l}\mathbf{A} \\
\mathbf{K}\end{array}$ & G & $\mathbf{P}$ & $\mathbf{E}$ & $\begin{array}{l}\mathrm{CO} \\
\mathrm{T}\end{array}$ & $\begin{array}{l}\mathbf{C I} \\
\mathbf{P}\end{array}$ & $\begin{array}{l}\mathbf{O} \\
\mathbf{F}\end{array}$ & $\begin{array}{l}\mathbf{V} \\
\mathbf{A}\end{array}$ & $\begin{array}{l}\mathbf{L} \\
\mathbf{Z}\end{array}$ & $\begin{array}{l}\text { CL } \\
\text { I }\end{array}$ & $\begin{array}{l}\text { CLO } \\
\mathrm{X}\end{array}$ & $\begin{array}{l}\mathbf{C} \\
\mathbf{X}\end{array}$ & $\begin{array}{l}\mathbf{C} \\
\mathbf{Z}\end{array}$ & CPM & $\begin{array}{l}\text { PI } \\
\text { T }\end{array}$ & $\begin{array}{l}\text { CA } \\
\mathbf{Z}\end{array}$ & $\mathbf{M}$ & I \\
\hline 1 & $\begin{array}{l}\text { Pseudomonas } \\
\text { aeruginosa }\end{array}$ & - & $S$ & $S$ & - & - & $R$ & $R$ & $S$ & - & - & - & - & - & - & $S$ & $S$ & $S$ & $S$ & $S$ \\
\hline 2 & $\begin{array}{l}\text { Staphylococcus } \\
\text { aureus }\end{array}$ & - & - & $S$ & $R$ & $S$ & $R$ & $R$ & $R$ & $S$ & $S$ & - & - & - & - & - & - & - & - & - \\
\hline 3 & $\begin{array}{l}\text { Staphylococcus } \\
\text { haemolyticus }\end{array}$ & - & - & $R$ & $R$ & $R$ & $R$ & $R$ & - & $S$ & $S$ & $R$ & - & - & - & - & - & - & - & - \\
\hline 4 & $\begin{array}{l}\text { Staphylococcus } \\
\text { epidermidis }\end{array}$ & - & - & $R$ & $R$ & $S$ & $R$ & $R$ & - & $S$ & $S$ & $S$ & - & - & - & - & - & - & - & - \\
\hline 5 & Other CoNS & - & - & $S$ & $R$ & $S$ & $R$ & $R$ & $R$ & $S$ & $S$ & - & $R$ & $R$ & $R$ & - & - & - & - & - \\
\hline 6 & MR CoNS & - & - & $S$ & $R$ & $R$ & $R$ & $R$ & $R$ & $S$ & $S$ & $R$ & - & - & - & - & - & - & - & - \\
\hline 7 & MS CoNS & - & - & $S$ & $R$ & $R$ & $R$ & $R$ & $R$ & $S$ & $S$ & $R$ & - & $S$ & $S$ & - & - & - & - & - \\
\hline 8 & MRSA & - & - & $S$ & $R$ & $S$ & $S$ & $S$ & - & $S$ & $S$ & - & $R$ & - & $R$ & - & - & - & - & - \\
\hline 9 & Escherichia coli & $R$ & $S$ & $S$ & - & - & $S$ & $R$ & - & - & - & - & - & $S$ & - & $S$ & $S$ & - & $S$ & $S$ \\
\hline 10 & $\begin{array}{l}\text { Enterobacter } \\
\text { cloacae }\end{array}$ & - & $S$ & $R$ & - & - & $S$ & $R$ & - & - & - & - & - & - & - & $R$ & $R$ & - & $S$ & $S$ \\
\hline 11 & $\begin{array}{l}\text { Enterobacter } \\
\text { aerogenes }\end{array}$ & $R$ & $S$ & $S$ & - & - & $S$ & - & - & - & - & - & - & - & - & $S$ & $S$ & - & - & $S$ \\
\hline 12 & $\begin{array}{l}\text { Acinetobacter } \\
\text { baumannii }\end{array}$ & $R$ & - & $S$ & - & - & $S$ & $R$ & - & - & - & - & - & - & - & $S$ & $S$ & $S$ & $R$ & $R$ \\
\hline 13 & $\begin{array}{l}\text { Acinetobacter } \\
\text { species }\end{array}$ & $R$ & $R$ & $R$ & - & - & $R$ & $R$ & - & - & - & - & - & - & - & $R$ & $S$ & $S$ & $R$ & $S$ \\
\hline 14 & Proteus mirabilis & $R$ & $S$ & $R$ & - & - & $R$ & $R$ & - & - & - & - & - & - & - & $S$ & $S$ & - & $R$ & $R$ \\
\hline
\end{tabular}

Fig.1 Predominance of gender

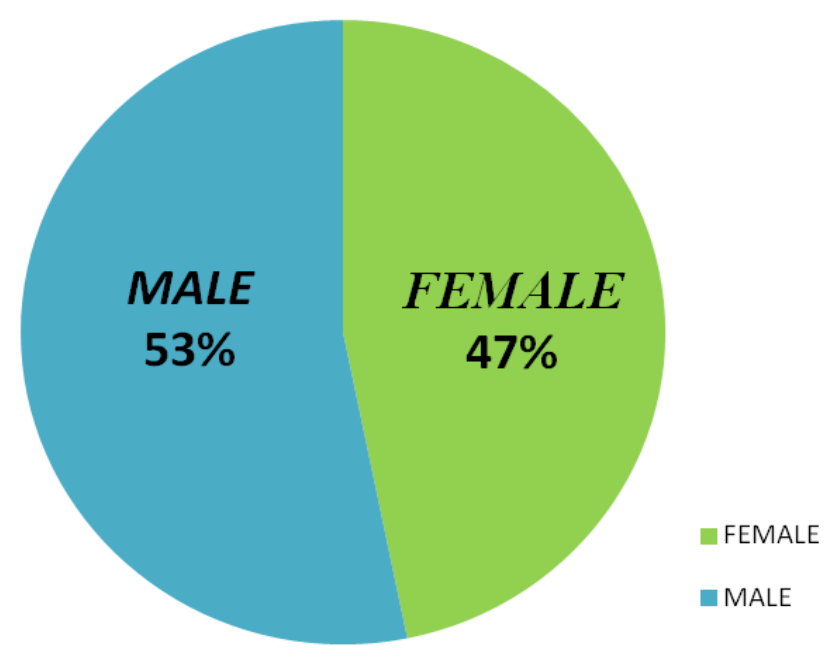


Fig.2

\section{Figure 2: Bacterial and Fungal Infection Ratios}

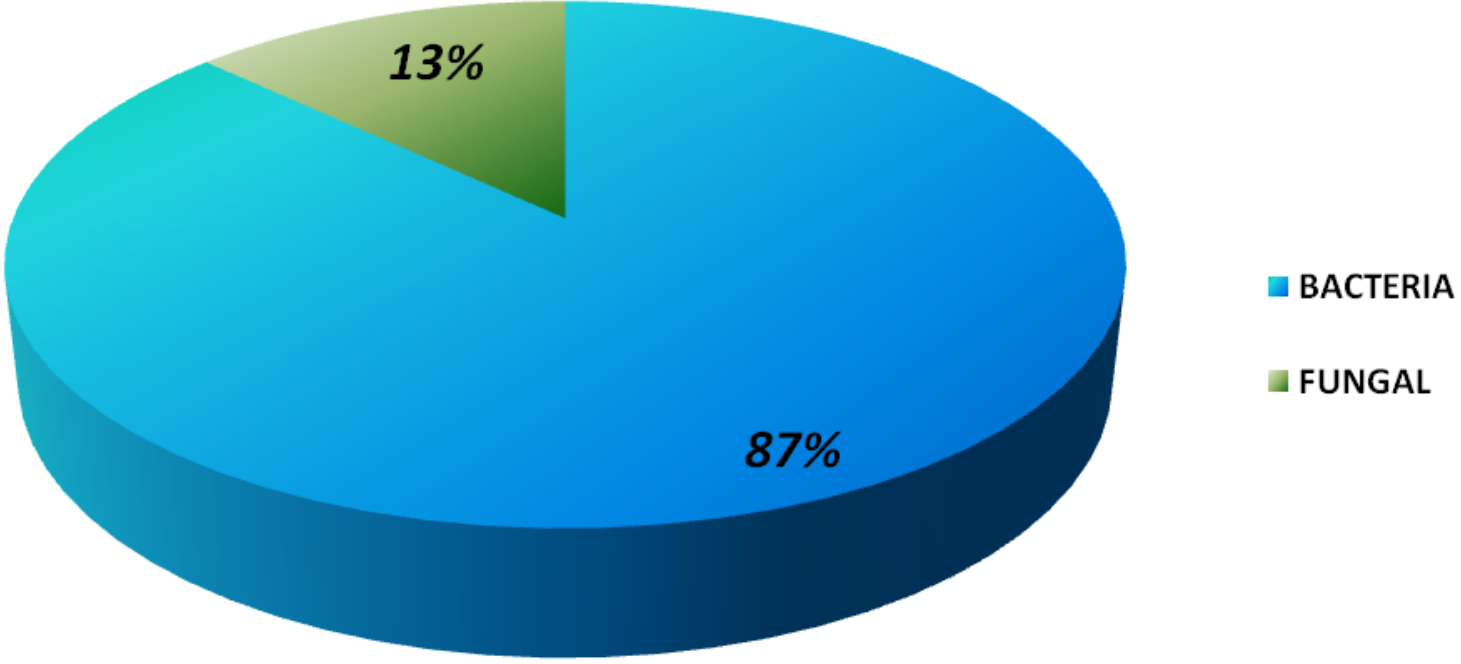

Fig.3

Figure 3: Age- and Gender- wise Distribution of Patients

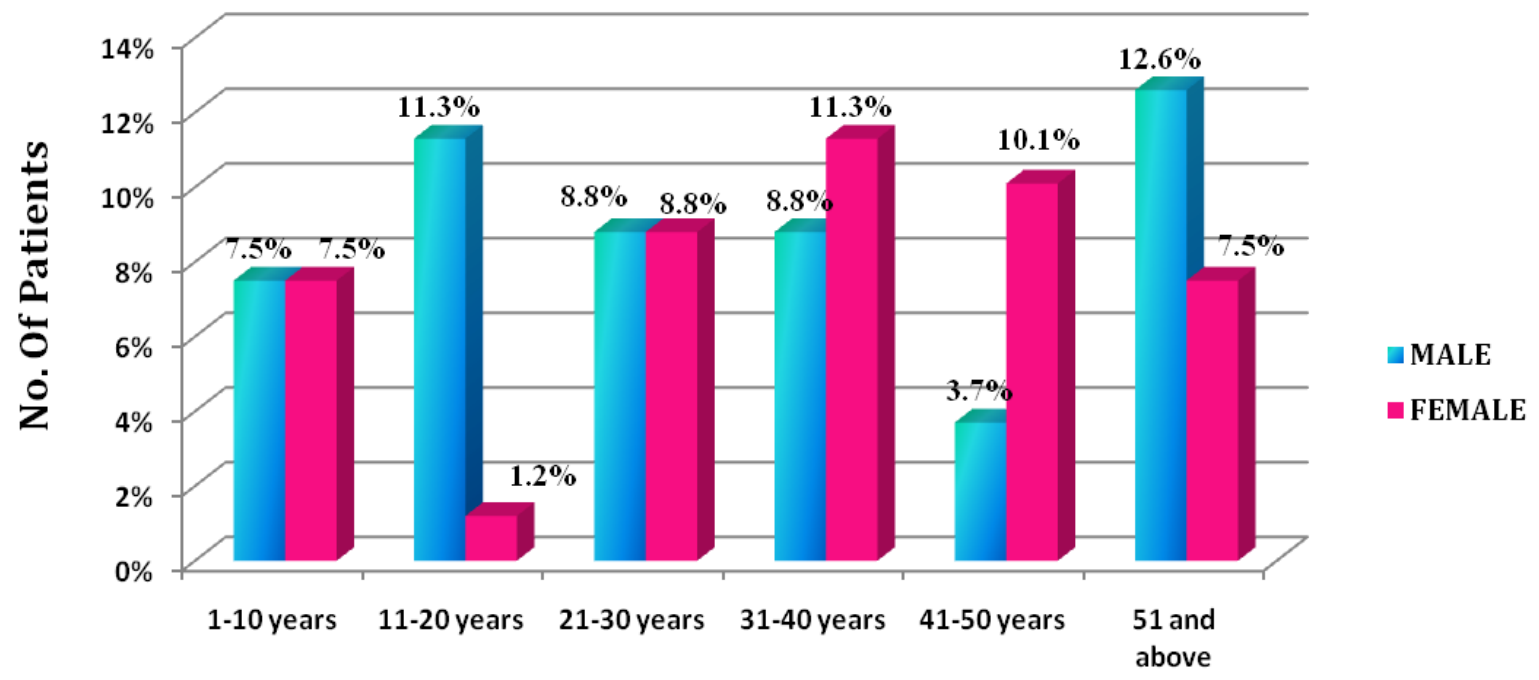

Age Group 
Fig.4

\section{Figure 4: Common Bacteria Causing Otitis Media}

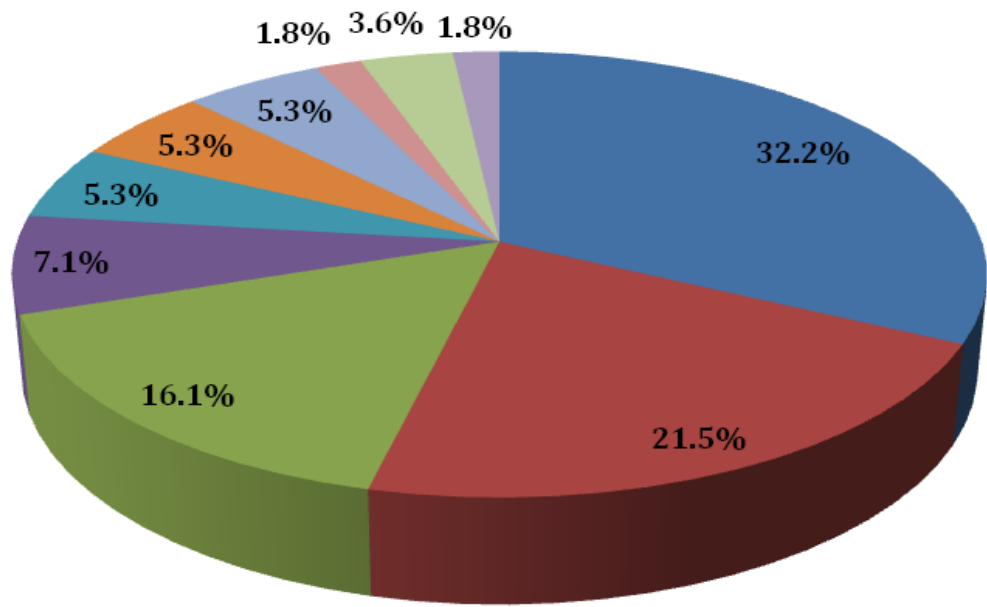

- Pseudomonas aeruginosa

- Staphylococcus aureus

- CoNS

- Acinetobacter species

acinetobacter baumannii

Escherichia coli

Enterobacter cloacae

Enterobacter aerogenes

Proteus mirabilis

MRSA

Fig.5

\section{Figure 5: Common Fungi Causing Otitis Media}

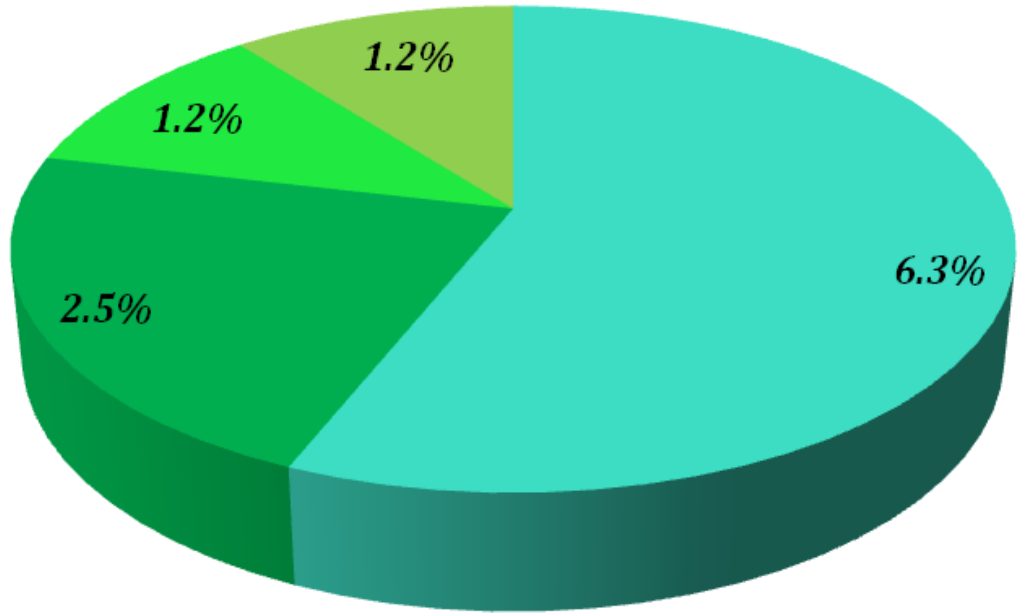

Candida non-albicans

Aspergillus species

Aspergillus fumigatus

Aspergillus niger 
Antifungal resistance is still under raise. Azole group of drugs and Amphotericin B are the common anti fungal drugs which can be used to treat these isolates causing otitis media in concordance with other studies.

In conclusion, among 79 patients diagnosed with Otitis Media, Pseudomonas aeruginosa was the most common bacteria involved followed by Staphylococcus aureus. Majority of the bacterial gram positive isolates were found to be sensitive to Vancomycin, Linezolid and gram negative isolates were found sensitive to combination drugs Piperacillin-tazobactum. The common fungi involved were Candida non albicans followed by Aspergillus species. Hence treatment at the appropriate stage with suitable drug and dose is significant in preventing complications due to Otitis Media.

\section{References}

1. SK Saranya- Bacteriological and Mycological Profile of Chronic Suppurative Otitis Media In A Tertiary Teaching Hospital, Trichy, Tamilnadu: International Journal of Pharmaceutical Science Invention. www.ijpsi.org//Volume 4 Issue 1// January 2015//pp.13-19

2. Sunilkumar Birdar and C.Roopa - Study of Microbiological Profile and their Antibiogram in Patients with Chronic Suppurative Otitis Media: International Journal of Current Microbiology and Applied Sciences ISSN: 2319-7706 Volume 4 Number 9 (2015) pp.981-985, http://www.ijcmas.com

3. Krista Vaidya - Bacteriological and Mycological profile of Chronic Suppurative Otitis Media among patients visiting Dhulikhel Hospital: ACCLM 1(1) 37-41(2015)

4. Dr.Asifa Nazir - Aerobic bacteriology of chronic suppurative otitis media: a hospital based study: International
Journal of Research in Medical Sciences. Nazir A et al., Int J Res Med Sci. 2014 Nov;2(4):1521-1525. www.msjonline.org

5. Otitis Media in Children: Review ArticleOpen Journal of Pediatrics, 2014,4,47-53

6. Rajat Prakash, Deepak Juyal, Neelam Sharma - Microbiology of Chronic Suppurative Otitis Media in a Tertiary Care Setup of Uttarakhand State, India: North American Journal of Medical Sciences-Med know Publications.

7. Ali Qureishi, Yan Lee, Matija Daniel Update on otitis media- prevention and treatment: Infection and Drug ResistanceDove Press.

8. Mansoor.T., Musani M., Khalid G., Kamal M. - Pseudomonas aeruginosa in Chronic Suppurative Otitis Media: Sensitivity Spectrum against various Antibiotics in Karachi: J Ayub Med Coll Abbottabad, 2009; 21(2): 120 - 123

9. Kumar H., Seth S. - Bacterial and Fungal Study of 100 cases of Chronic Suppurative Otitis Media: Journal of Clinical and Diagnostic Research, Nov 2011; 5(6): 1224 - 1227

10. Poorey, V.K., Arati Iyer - Study of bacterial flora in CSOM and its clinical significance, 2002: Indian J. Otolaryngol Head Neck Surg., 54: 91-5.

11. Deb, T., Ray, D.- A study of the bacteriological profile of chronic suppurative otitis media in agartala, 2012: Indian J. Otolaryngol. Head Neck Surg., 64: 326-9.

12. Agrawal, A., Dharmendra, K., Ankur, G., Sapna, G., Namrata, S., Gaurav, K. Microbiological profile and their antimicrobial sensitivity pattern in patients of otitis media with ear discharge, 2013: Indian J. Otol., 19: 1.

13. Shyamala R., Reddy SP. - The study of bacteriological agents of chronic suppurative otitis media - Aerobic culture and evaluation: Journal of Microbiology 
and Biotechnology Research, 2012; 2(1): $152-162$

14. Sanjana R.K, Singh Y.L and Reddy N.S.Aerobic bacteriology of Chronic suppurative otitis media (CSOM) in a tertiary care hospital: A retrospective study: Nepal Med Coll J., 2011; 7(2): 1-8.
15. Shyamala R, Reddy PS. - Incidence and sensitivity pattern of Pseudomonas aeruginosa in chronic suppurative otitis media in South Indian Rural Population: J Microbiol Biotech Res 2012; 2(2): 34650.

\section{How to cite this article:}

Bala Ashwathy, R.M. and Neelusree, P. 2019. Bacteriological and Fungal Profile of Otitis Media. Int.J.Curr.Microbiol.App.Sci. 8(09): 122-131.

doi: https://doi.org/10.20546/ijcmas.2019.809.017 